\section{Use of Antivenom in Vipera berus Bites-A Comment}

To the Editor:

In their recent letter, Moser and Roeggla report severe envenoming by Vipera berus in a 12-year-old boy. ${ }^{1}$ Shock, upper airway narrowing, and abdominal pain developed within 10 minutes of the bite. These are familiar early anaphylactic features of envenoming by $V$ berus, possibly attributable to venom autacoids. ${ }^{2,3}$ After an initial response to symptomatic treatment, hemorrhagic swelling spread rapidly to involve the bitten extremity and adjacent hemithorax and he suffered other complications. Such severe systemic and local envenoming fulfils all published criteria for antivenom treatment and yet none was given for fear of an antivenom reaction. However, the only reference cited by the authors to support their nihilistic decision is a study of rattlesnake bites in children in the United States at a time when the notoriously reactogenic Wyeth antivenom was in use (1988-1998). Wyeth was subsequently replaced by the much safer CroFab (Protherics Inc, Nashville, TN). ${ }^{4}$ The risk of such reactions with currently available antivenoms for use in bites by European vipers is very low, ${ }^{2,3,5}$ whereas the risk of death from Vipera bites in Europe is a compelling reason to use antivenom in the treatment of severe envenoming, especially in children. We are anxious to correct the authors' misunderstanding about the validity of the "Stockholm criteria" for antivenom treatment in children. This is supported in the literature, including references quoted by Moser and Roeggla and below. ${ }^{5}$ In fact, the agreed indications should be applied even more liberally in children and pregnant women because of the risk of more severe consequences of envenoming. ${ }^{6}$ A most important effect of antivenom is that it will prevent or ameliorate the widespread and disabling local swelling. ${ }^{7}$ Although initial, dramatic systemic symptoms, often reminiscent of anaphylaxis, can sometimes be managed symptomatically, antivenom treatment shortens the period of circulatory instability, reducing the need for intravenous fluids and hence the risk of volume overload. This is particularly important in small children as pulmonary edema may develop late in the course when large volumes of extravasated fluid in the extremities and trunk are being reabsorbed.

Christine B. M. Karlson-Stiber, MD Swedish National Poison Centre Stockholm, Sweden

Hans E. Persson, MD Swedish Poisons Information Center Stockholm, Sweden

David A. Warrell, MA, DM, DSc, FRCP University of Oxford Oxford, $U K$

\section{References}

1. Moser B, Roeggla G. Vipera berus bite in a child, with severe local symptoms and hypotension. Wilderness Environ Med. 2009;20:90-104.

2. Karlson-Stiber C, Salmonson H, Persson H. A nationwide study of Vipera berus bites during one year-epidemiology and morbidity of 231 cases. Clin Toxicol (Phila). 2006;44: 25-30.

3. Warrell DA. Treatment of bites by adders and exotic venomous snakes. Br Med J. 2005;331(7527):1244-1247.

4. Dart RC, Seifert SA, Boyer LV, et al. A randomized multicenter trial of crotalinae polyvalent immune Fab (ovine) antivenom for the treatment for crotaline snakebite in the United States. Arch Intern Med. 2001;161:2030-2036.

5. de Haro L, Lang J, Bedry R, Guelon D, Harry P, MarchalMazet F, Jouglard J. Envenimations par vipères européennes. Étude multicentrique de tolérance du Viperfav $^{\mathrm{TM}}$, nouvel antivenin par voie intraveineuse. Ann $\mathrm{Fr}$ Anesth Reanim. 1998;17:681-687.

6. Persson H, Karlson-Stiber C. Clinical features and principles of treatment of envenoming by European vipers. In: Envenomings and Their Treatments. Paris, France: Institute Pasteur, Foundation Marcel Mèrieux; 1996:281-292.

7. Theakston RD, Reid HA. Effectiveness of Zagreb antivenom against envenoming by the adder, Vipera berus. Lancet. 1976;2(7977):121-123.

\section{In Reply to "Use of Antivenom in Vipera berus Bites-A Comment"}

\section{To the Editor:}

We would like to thank Drs Persson, Stiber, and Warrell for their helpful comments on our case report of severe envenoming by Vipera berus in a 12-year-old child. ${ }^{1} \mathrm{We}$ agree that the situation at the time of admission fulfilled the reported criteria for antivenom treatment. The boy was not treated with antivenom therapy because nearly all symptoms of envenoming apart from rapidly spreading swelling improved rather quickly under supportive therapy and the risk of antivenom therapy was considered to be higher than the potential benefit.

The question of when to administer antivenom may be clearly answered within the community of snake bite specialists. In clinical medicine, however, some controversy and confusion still remain. Professor Warrell acknowledges that specific antidotes are underused in the United Kingdom. ${ }^{2}$ This may be true in continental Europe as well, and we would favor the publication of guidelines addressed specially to the therapy of children in a general medical journal as an amendment to his clinical review in the British Medical Journal published in 2005. 
Berthold Moser, MD Bolzano, Italy

Georg Roeggla, MD

Neunkirchen, Austria

\section{References}

1. Moser B, Roeggla G. Vipera berus bite in a child, with severe local symptoms and hypotension. Wilderness Environ Med. 2009;20:100-101.

2. Warrell DA. Treatment of bites by adders and exotic venomous snakes. BMJ. 2005;331:1244-1247.

\section{UK High Altitude Research: A report from the Birmingham Medical Research Expeditionary Society (BMRES) Altitude Research Conference, December 4, 2009, held at the Birmingham Medical Institute, United Kingdom}

\section{To the Editor:}

We would like to report on the 1-day altitude medicine research meeting held at the Birmingham Medical Institute, Birmingham, UK on December 4, 2009. The meeting provided an opportunity for researchers from several different high altitude research groups in the United Kingdom to present their findings and share experiences from recent laboratory and field work. In addition, the meeting aimed to welcome newcomers, foster collaboration, and encourage more individuals to get involved in altitude research.

Data presented in the meeting drew from several recent expeditions and chamber studies, demonstrating how active these UK groups currently are. Recent projects included the University of Bangor trip to the European Alps, the BMRES hypoxic chamber studies in Glamorgan and field studies in Northern Chile, University of Oxford chamber and field studies, University of Edinburgh research at Kilimanjaro, and Caudwell Xtreme Everest expeditions to Cho Oyu and Everest.

The first of the morning's sessions concentrated on molecular studies on oxidative and nitrosative stress. Professor Martin Feelisch (University of Warwick) began the meeting with a summary of the role of nitric oxide in the body's response to hypoxia. Professor Damian Bailey (University of Glamorgan) presented an overview of current evidence for the production of free radicals in hypoxia and demonstrated that radical production correlates with impaired cerebral autoregulation. He presented the hypothesis that blood-brain barrier function becomes dysregulated in hypoxia, and may be a contributory factor to the development of high altitude cerebral edema (HACE). Nicky Kolfshoten (Caudwell Xtreme Everest) presented a study that examined the potential correlation between headache score and head size (a proxy measure of intracranial volume) in trekkers ascending to Everest base camp, and Andrew Sutherland (University of Oxford) gave an update on optic nerve sheath diameter and correlation with acute mountain sickness (AMS) scores. These studies prompted a vigorous debate about whether AMS and HACE are the result of raised intracerebral volume or intracranial pressure.

Included in a session on training and acclimatization were presentations on studies into weight loss and gastrointestinal function at altitude. Data from Xtreme Everest, presented by Maryam Khoshravi, investigated weight loss on two separate Himalayan expeditions to Cho Oyo and Everest, and an intrinsic genetic basis for high altitude weight loss was proposed. This was complemented by a BMRES study investigating the mechanism of high altitude gastrointestinal dysfunction, which measured gut blood flow in response to food ingestion.

The day highlighted the volume of current work investigating pulmonary hypertension at altitude, especially at the University of Oxford Department of Physiology, Anatomy and Genetics: Mari Herigstad presented data from a chamber study looking at the effect of hypoxia on the ability of the pulmonary vasculature to dilate on exercise, and Nick Talbot described his work on the effect of iron supplementation and depletion on pulmonary hypertension. Cameron Holloway (University of Oxford) presented some fascinating results that may shed light on mechanisms of cardiac function at altitude, of which we eagerly await full publication. Attendees were also reminded of the high altitude pulmonary edema (HAPE) database (www.hape.org.uk) which now has more than 600 possible cases of HAPE registered, and people are encouraged to look at the website, and publicize it when traveling at altitude.

Between sessions there was time available to view the posters, providing a valuable opportunity for some of the younger members of the research groups to present and discuss their work. The prize for best poster was jointly awarded to Karl New and Sarah Major. The Research award was won by Cameron Holloway, and Maryam Khoshravi was given the Young Investigator award. In addition, a hotly contested photographic competition ran throughout the day, which was won by Paul Firth and Hannah Collins. During the afternoon David Hillebrandt gave an update on the Diploma in Mountain Medicine (Univer- 